\title{
A novel blood-pooling MR contrast agent: Carboxymethyl-diethylaminoethyl dextran magnetite
}

\author{
AKINAGA SONODA, NORIHISA NITTA, KEIKO TSUCHIYA, AYUMI NITTA-SEKO, \\ SHINICHI OHTA, HIDEJI OTANI and KIYOSHI MURATA
}

Department of Radiology, Shiga University of Medical Science, Otsu, Shiga 520-2192, Japan

Received September 19, 2015; Accepted October 7, 2016

DOI: $10.3892 / \mathrm{mmr} .2016 .5874$

\begin{abstract}
Gadofosveset trisodium is available as a prolonged pooling vascular contrast agent for magnetic resonance imaging. As gadolinium $(\mathrm{Gd})$-based agents may increase the risk fornephrogenic systemic fibrosis in patients with severe renal insufficiency, the present study synthesized carboxymethyl-diethylaminoethyl dextran magnetite (CMEADM) particles as a blood-pooling, non-Gd-based contrast agent. CMEADM particles carry a negative or positive charge due to the binding of amino and carboxyl groups to the hydroxyl group of dextran. The present study evaluated whether the degree of charge alters the blood-pooling time. The evaluation was performed by injecting four groups of three Japanese white rabbits each with $\mathrm{CMEADM}^{-}$, $\mathrm{CMEADM}^{2-}, \mathrm{CMEADM}^{+}$(surface charges: -10.4, -41.0 and $+9.6 \mathrm{mV}$, respectively) or with ultrasmall superparamagnetic iron oxide (USPIO; $-11.5 \mathrm{mV})$. The relative signal intensity $\left(\mathrm{SI}_{\mathrm{rel}}\right)$ of each was calculated using the following formula: $\mathrm{SI}_{\mathrm{rel}}=(\mathrm{SI}$ post-contrast - SI pre-contrast / SI pre-contrast) x 100. Following injection with the CMEADMs, but not with USPIO, the in vivo pooling time was prolonged to $>300 \mathrm{~min}$. No significant differences were attributable to the electric charge among the $\mathrm{CMEADM}^{-}$, CMEADM2- or and $\mathrm{CMEADM}^{+}$particles when analyzed with analysis of variance and Tukey's HSD test. Taken together, all three differently-charged CMEADM2 particles exhibited prolonged vascular enhancing effects, compared with the USPIO. The degree of charge of the contrast agents used in the present study did not result in alteration of the prolonged blood pooling time.
\end{abstract}

\section{Introduction}

Ultrasmall superparamagnetic iron-oxide nanoparticles (USPIOs) have been used as negative contrast agents. They exert T2- and T1-shortening effects, and their potential as

Correspondence to: Dr Akinaga Sonoda, Department of Radiology, Shiga University of Medical Science, Seta Tsukinowa-cho, Otsu, Shiga 520-2192, Japan

E-mail: akinaga@belle.shiga-med.ac.jp

Key words: magnetic resonance angiography, iron, dextran an angiographic contrast agent has been investigated $(1,2)$. Its long blood half-life makes it possible to use USPIO as a blood-pooling agent during the early phase of magnetic resonance angiography (MRA), however, USPIO is not suitable for the late phase of MRA, due to the presence of phagocytic Kupffer cells (3). Gadofosveset, a gadolinium (Gd)-based blood-pooling agent, has been approved by the U.S. Food and Drug Administration for aortoiliac MRA in certain patients (4). A single dose can be injected for first-pass imaging; a post-injection interval of 10 to $20 \mathrm{~min}$ has been suggested for optimal steady-state imaging (5). However, the use of gadofosveset trisodium may increase the risk for nephrogenic systemic fibrosis (NSF) in patients with renal impairment (6).

Xiao et al (7) and Nitta et al (8-10) reported a novel, long-circulating blood-pooling contrast agent, which involved iron-based substances. Nitta et al synthesized carboxymethyl-diethylaminoethyl dextran magnetite (CMEADM) particles (8-10) and used this Gd-free contrast agent in experimental magnetic resonance imaging (MRI) studies $(8,9)$. As with superparamagnetic iron-oxide nanoparticles (SPIOs) and USPIOs, CMEADM is based on iron-oxide. As CMEADM is coated with polymers, including dextran, to prevent aggregation, its pooling time in blood vessels is longer, compared with USPIO (11-13), and its surface carries a negative or a positive charge due to the binding of amino and carboxyl groups to the hydroxyl group of dextran (Fig. 1). The present study evaluated whether the degree of charge on CMEADM altered the blood pooling time in rabbits.

\section{Materials and methods}

Animals. All experiments were approved in advance by the ethical animal experiments committee of Shiga University of Medical Science (Otsu, Japan), and performed according to the Animal Care Guidelines of Shiga University of Medical Science. Female Japanese white rabbits $(3.0 \mathrm{~kg})$ were purchased from Japan SLC, Inc. (Tokyo, Japan). Prior to each MRI session, the rabbits were anesthetized with intramuscular injections of a mixture of ketaminehydrochloride $(25 \mathrm{mg} / \mathrm{kg}$ Ketalar 50; Sankyo Yell Yakuhin Co., Ltd., Tokyo, Japan) and medetomidine hydrochloride $(0.1 \mathrm{mg} / \mathrm{kg}$; Domitor; Meiji Seika Co., Ltd., Tokyo, Japan). All animals were housed in a temperature-controlled room $\left(24 \pm 1^{\circ} \mathrm{C}\right)$ on a 12 -h light/12-h dark cycle. They had access to standard laboratory chow ad libitum. 


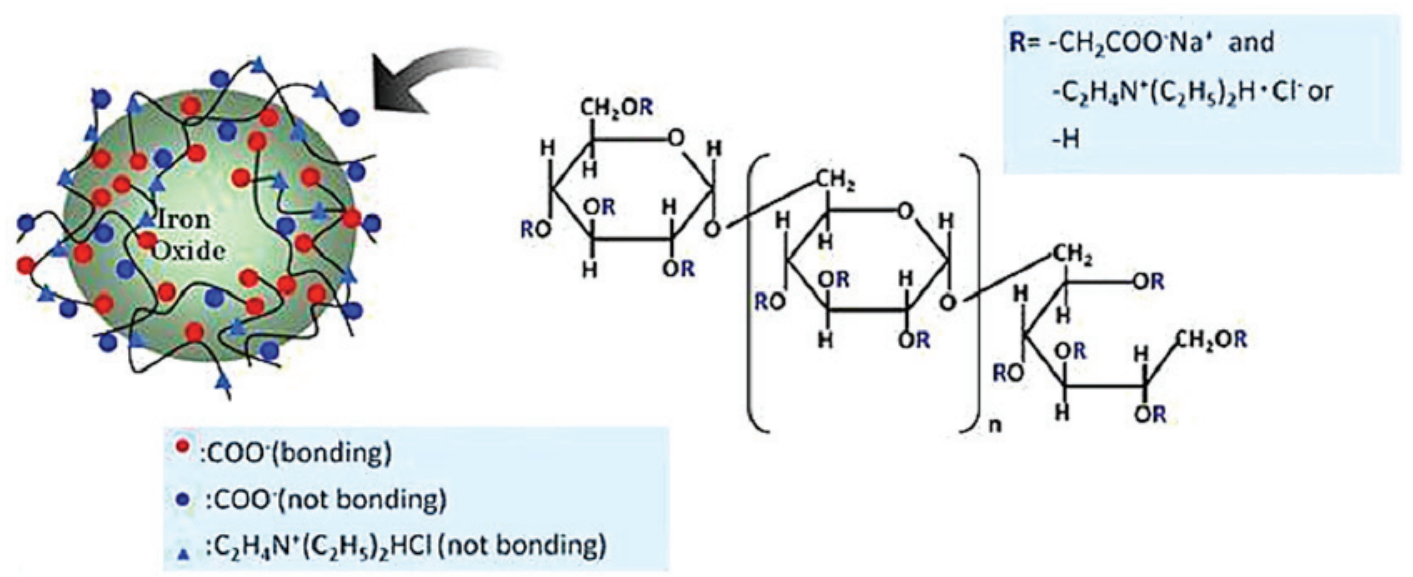

Figure 1. Surface of carboxymethyl-diethylaminoethyl dextran magnetite particles carries either a negative or positive charge due to the binding of amino and carboxyl groups to the hydroxyl group of dextran.

A total of 12 Japanese white rabbits were randomly divided into four groups of three rabbits. The animals received an intravenous injection of $40 \mu \mathrm{mol} \mathrm{Fe} / \mathrm{kg}$ of differently-charged CMEADM or USPIO (Table I).

Following pre-scanning, one of four types of iron nanoparticles, $\mathrm{CMEADM}^{-}, \mathrm{CMEADM}^{2-}$ and $\mathrm{CMEADM}^{+}$with surface charges of $-10.4,-41.0$, and $+9.6 \mathrm{mV}$, respectively, or USPIO $(-11.5 \mathrm{mV})$, was injected intravenously into the auricular vein. All contrast agents were obtained from Meito Sangyo Co., Ltd. (Tokyo, Japan). MRA images were obtained immediately following injection, and at 30,60, 180 and 300 min post-injection.

MRI. MRI scanning was performed on a $1.5 \mathrm{~T}$ MRI instrument (SIGNA Excite HDx; GE Healthcare Life Sciences, Shanghai, China) with a circularly polarized head coil and the following scanning parameters: 3D fast-spoiled gradient echo; repetition time, $9.0 \mathrm{~ms}$; echo time, $1.4 \mathrm{~ms}$; flip angle, $25^{\circ} \mathrm{C}$; field-of-view, $320 \times 240 \mathrm{~mm}$; slice thickness, $1 \mathrm{~mm}$; matrix, 256x256.

The relative signal enhancement, or relative signal intensity $\left(\mathrm{SI}_{\mathrm{rel}}\right)$, was measured at the abdominal aorta and the inferior vena cava (IVC) on 1-mm-thick coronal images. $\mathrm{SI}_{\text {rel }}$ was calculated using the following formula:

$\mathrm{SI}_{\mathrm{rel}}=(\mathrm{SI}$ post-contrast - SI pre-contrast / SI pre-contrast $) \times 100$

These values were calculated by dividing the signal of the aorta or IVC by the background SI observed over time. Subsequent to the experiments, rabbits were sacrificed by injecting the heart with an overdose of pentobarbital (Dainippon Sumitomo Pharma Co., Ltd., Tokyo, Japan).

Statistical analysis. The results were analyzed by performing analysis of variance followed by Tukey's HSD test using IBM SPSS 20 statistical software (IBM SPSS, Armonk, NY, USA) for Windows. $\mathrm{P}<0.05$ was considered to indicate a statistically significant difference.

\section{Results}

Visibility of vasculature. The vessels were clearly visualized. Compared with the group injected with USPIO, the thoracic and abdominal aorta, and the IVC manifested significantly higher SI values following the injection of the three types of CMEADM. Even at 300 min-post injection, the thoracic and abdominal aorta, and the IVC were clearly visible (Fig. 2).

Irrespective of their charge, with all three CMEADMs used in the present study, the vascular enhancing effect persisted for up to $300 \mathrm{~min}$ on the MRA images. By contrast, with the conventional USPIO, the intravascular SI was markedly decreased and had almost disappeared at $180 \mathrm{~min}$.

Relative signal enhancement. $\mathrm{SI}_{\mathrm{rel}}$ continued to be present in the abdominal aorta and IVC 30,60, 180 and $300 \mathrm{~min}$ following the delivery of $\mathrm{CMEADM}^{-}, \mathrm{CMEADM}^{2-}$ or $\mathrm{CMEADM}^{+}$(Figs. 3 and 4). At 180 and $300 \mathrm{~min}$, the elevation of $\mathrm{SI}_{\text {rel }}$ persisted on all the CMEADM- images, but not on the USPIO images. No significant differences were found in the enhancing abilities of CMEADM- $\mathrm{CMEADM}^{2-}$ or $\mathrm{CMEADM}^{+}$at 30 min post-injection.

\section{Discussion}

The present study compared standard USPIO and CMEADMs for their efficacy as blood-pooling MR contrast agents. All three differently-charged CMEADMs (CMEADMU', $\mathrm{CMEADMU}^{2-}$ and $\mathrm{CMEADMU}^{+}$) elicited a sufficiently prolonged vascular enhancing effect in the rabbits. Investigations are underway to determine whether these contrast agents qualify as novel blood-pooling MR contrast agents in the clinical setting.

The present study documented that, with the newly synthesized iron nanoparticles, CMEADM, the retention of $\mathrm{SI}_{\text {rel }}$ in the blood vessels of the rabbits was prolonged. As these agents are Gd-free, they can be used in patients with renal impairment, including stage 4 or 5 chronic kidney disease (glomerular filtration rate $<30 \mathrm{ml} / \mathrm{min}$ per $1.73 \mathrm{~m}^{2}$ ), who may be at risk for NSF when Gd agents are used. Although the injection of iron oxide nanoparticles may elicit cellular disorders, they may represent an alternative contrast agent for use in patients with renal impairment (14).

Conventional USPIOs have been used as negative contrast agents. However, as documented in the present study, their 
Table I. Properties of the injected differently charged CMEADM or USPIO contrast agents.

\begin{tabular}{lccccc}
\hline $\begin{array}{l}\text { Contrast } \\
\text { agent }\end{array}$ & $\begin{array}{c}\text { Particle } \\
\text { size }(\mathrm{nm})\end{array}$ & $\begin{array}{c}\text { Iron concentration } \\
(\mathrm{mg} / \mathrm{ml})\end{array}$ & $\begin{array}{c}\text { T2 relaxivity } \\
(\mathrm{r} 2: \mathrm{mM} / \mathrm{s})\end{array}$ & $\begin{array}{c}\text { T1 relaxivity } \\
(\mathrm{r} 1: \mathrm{mM} / \mathrm{s})\end{array}$ & $\begin{array}{c}\text { Surface charge } \\
(\mathrm{mV})\end{array}$ \\
\hline $\mathrm{CMEADM}^{-}$ & 32.0 & 15.0 & 114.0 & 34.0 & -10.4 \\
$\mathrm{CMEADM}^{2-}$ & 29.0 & 15.0 & 91.0 & 34.0 & -41.0 \\
$\mathrm{CMEADM}^{+}$ & 32.0 & 15.0 & 106.0 & 33.0 & 9.6 \\
USPIO & 28.0 & 15.0 & 95.0 & 34.0 & -11.5 \\
\hline
\end{tabular}

CMEADM, carboxymethyl-diethylaminoethyl dextran magnetite; USPIO, ultrasmall superparamagnetic iron-oxide nanoparticle.
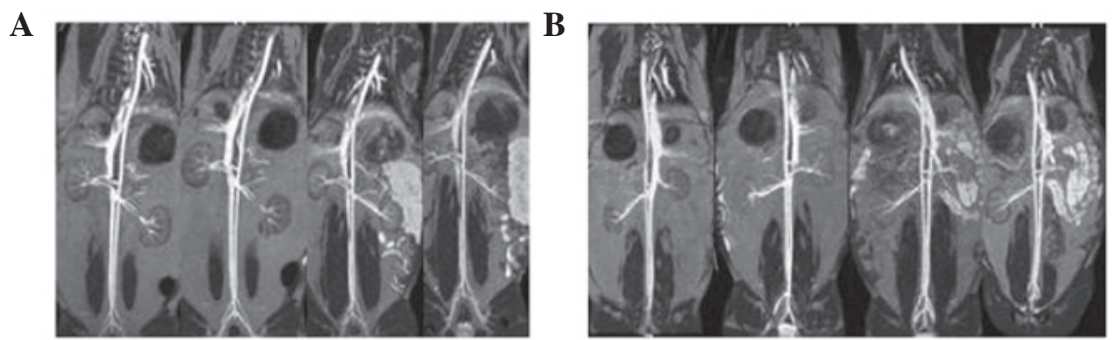

C

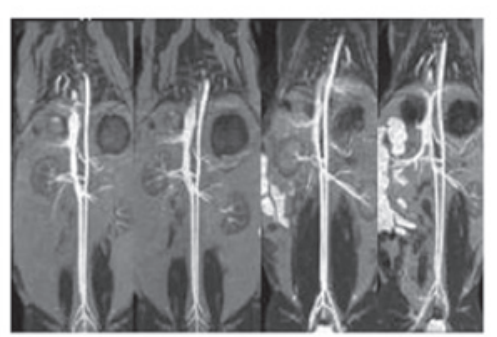

D

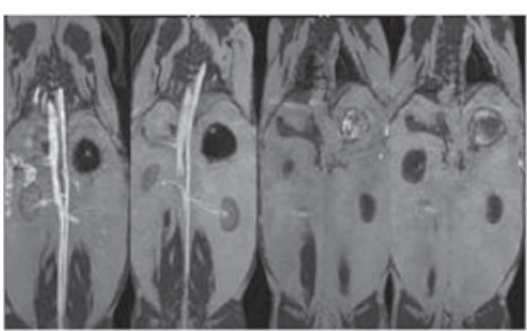

Figure 2. Vascular enhancement. On the magnetic resonance angiography images, the vascular enhancing effect persisted for up to 300 min with injections of (A) CMEADM-, (B) $\mathrm{CMEADM}^{2-}$ and (C) $\mathrm{CMEADM}^{+}$. By contrast, with (D) conventional USPIO, intravascular signal intensity was markedly decreased and almost absent at $180 \mathrm{~min}$. CMEADM, carboxymethyl-diethylaminoethyl dextran magnetite; USPIO, ultrasmall superparamagnetic iron-oxide nanoparticle.

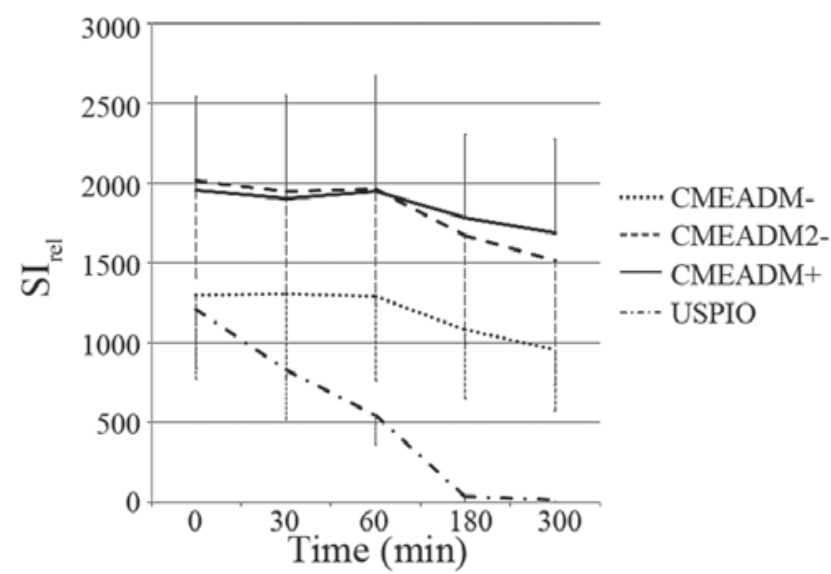

Figure 3. $\mathrm{SI}_{\text {rel }}$ patterns in the aorta. In the aorta, the $\mathrm{SI}_{\text {rel }}$ elicited by the three different CMEADMs remained high up to $60 \mathrm{~min}$ and then decreased. At 180 and $300 \mathrm{~min}, \mathrm{SI}_{\text {rel }}$ values were significantly higher in the $\mathrm{CMEADM}^{2}$ and $\mathrm{CMEADM}^{+}$groups, compared with the USPIO group $(\mathrm{P}<0.05)$. Data are presented as the mean of the three rabbits in each group. $\mathrm{SI}_{\mathrm{rel}}$, relative signal intensity; CMEADM, carboxymethyl-diethylaminoethyl dextran magnetite; USPIO, ultrasmall superparamagnetic iron-oxide nanoparticle.

pooling time was shorter, compared with the durations observed in the CMEADM groups. Smaller particles are less likely to be phagocytized, compared with large particles $(11,13,15)$,

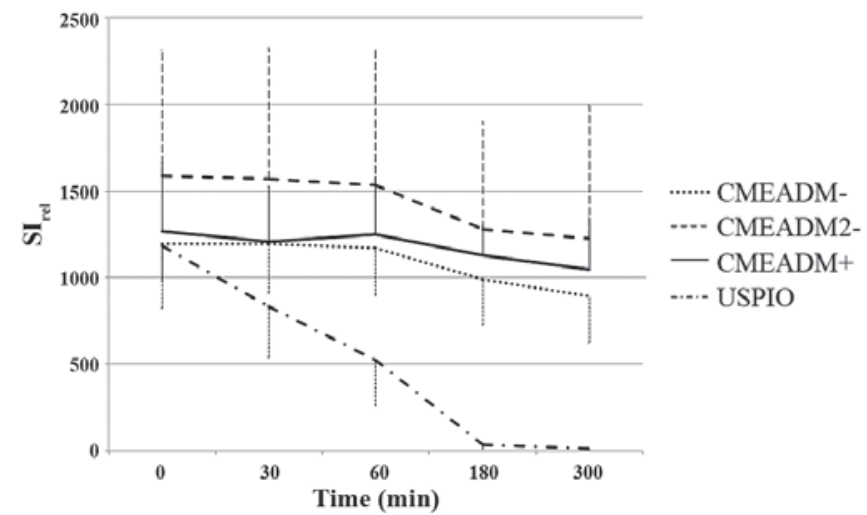

Figure 4. $\mathrm{SI}_{\text {rel }}$ patterns in the IVC. $\mathrm{SI}_{\text {rel }}$ patterns in the IVC were similar to those in the aorta. At $180 \mathrm{~min}$, signal enhancement in the IVC was significantly higher in all charged CMEADMs groups, compared with the USPIO group $(\mathrm{P}<0.05)$. At $300 \mathrm{~min}, \mathrm{SI}_{\text {rel }}$ was significantly higher for $\mathrm{CMEADM}^{2-}$, compared with USPIO $(\mathrm{P}<0.05)$. Data are presented as the mean of the three rabbits in each group. $\mathrm{SI}_{\text {rel }}$, relative signal intensity; IVC, inferior vena cava; CMEADM, carboxymethyl-diethylaminoethyl dextran magnetite; USPIO, ultrasmall superparamagnetic iron-oxide nanoparticle.

however, the sizes of CMEADM and USPIO particles are similar. According to Jo et al (16). iron oxide nanoparticles with positive surface potential interact ionically with the cell 
surface as it is negatively charged. Consequently, the cell internalization of nanoparticles is increased.

The present study hypothesized that the negatively charged surface may affect the pooling time as a result of the decreased likelihood of phagocytosis. The charge of the USPIO in the present study was $-11.5 \mathrm{mV}$. The present study synthesized three types of CMEADM with a similar charge of $-10.4 \mathrm{mV}$ $\left(\mathrm{CMEADM}^{-}\right)$, a lower charge of $9.6 \mathrm{mV}\left(\mathrm{CMEADM}^{+}\right)$and a higher charge of $-41.0 \mathrm{mV}\left(\mathrm{CMEADM}^{2+}\right)$, compared with that of USPIO, and calculated their $\mathrm{SI}_{\text {rel }}$ values. It was found that with all three types of CMEADM, irrespective of their charge, the blood-pooling time was prolonged. This suggested that their surface charge, whether positive or negative, did not affect the pooling time.

Iron nanoparticles, including USPIOs, are phagocytized in the liver and spleen, and metabolized via the same metabolic pathway as hemoglobin iron. However, although CMEADM may be metabolized via a similar pathway, these particles are different from conventional USPIOs, as the iron in CMEADM is covered by an increased quantity of dextran. It may be possible to retard their clearance from vessels by rendering their surface hydrophilic with poloxamers and poloxamines, including dextran (17). Covering CMEADM particles with dextran may reduce their recognition by phagocytes and/or their entrapment by Kupffer cells $(8,18)$. The superior pooling time of CMEADMs in the blood stream may reflect a hydrophilic effect, and investigations are underway to determine whether this is the case.

CMEADM particles are considered to have a longer half-life, compared with USPIOs, and may be more useful for long-term angiographic investigations in humans. Due to the long pooling time of CMEAD in vessels, a single administration of the agent may suffice for the pre- and post-procedure angiographic evaluation of patients undergoing percutaneous transluminal angioplasty of coronary arteries, stent placement (percutaneous coronary intervention) or aortic stent grafting (8). In addition, MRI examinations using CMEADM agents may be used for the diagnosis of patients with intermittent gastrointestinal bleeding. Although Gd contrast agents may elicit complications, including NSF, to the best of our knowledge, there have been no reports of patients with serious adverse effects elicited by the administration of iron nanoparticles to date.

The present study had a number of limitations. First, the number of rabbits included in the investigation was small. However, it was of a sufficient size to enable assessment of statistical significance, and the prolonged enhancement effect of CMEADM 180 min post-injection was clearly demonstrated. Therefore, the number of rabbits used was deemed sufficient to support the conclusions. Second, it was not possible to compare the CMEADM with emerging non-contrast MRA techniques, including quiescent-interval single-shot MRA, with respect to vessel visualization (19). Third, the present study found that visually confirmed vascular enhancement persisted for up to $300 \mathrm{~min}$. This may raise concerns regarding the wash-out kinetics of these agents. Although these agents do not elicit NSF or other renal complications, for example long elimination time, this is a significant limitation. Fourth, CMEADM particles are covered with an increased quantity of dextran, compared with USPIO. The dextran used for particle covering is the same substance used for ferucarbotran. Although the present study suggested that the use of CMEADM is safe, in rare instances, dextran has been reported to elicit severe anaphylactic reactions (20). Consequently, the safety of CMEADM requires further elucidation. Investigations are underway to determine the elimination routes and kinetics, and to obtain quantitative data.

\section{References}

1. Allkemper T, Bremer C, Matuszewski L, Ebert W and Reimer P: Contrast-enhanced blood-pool MR angiography with optimized iron oxides: Effect of size and dose on vascular contrast enhancement in rabbits. Radiology 223: 432-438, 2002.

2. Bremerich J, Bilecen D and Reimer P: MR angiography with blood pool contrast agents. Eur Radiol 17: 3017-3024, 2007.

3. Leung K: Ultrasmall superparamagnetic iron oxide nanoparticles conjugated with Ile-Pro-Leu-Pro-Phe-Tyr-Asn. In: Molecular imaging and contrast agent database (MICAD), Bethesda (MD) Fed. 23, 2010.

4. Bryson J, Reineke JW and Reineke TM: Macromolecular imaging agents containing lanthanides: Can conceptual promise lead to clinical potential? Macromolecules 45: 8939-8952, 2012.

5. Grist TM, Korosec FR, Peters DC, Witte S, Walovitch RC, Dolan RP, Bridson WE, Yucel EK and Mistretta CA: Steady-state and dynamic MR angiography with MS-325: Initial experience in humans. Radiology 207: 539-544, 1998.

6. Weller A, Barber JL and Olsen OE: Gadolinium and nephrogenic systemic fibrosis: An update. Pediatr Nephrol 29: 1927-1937, 2014.

7. Xiao W, Lin J, Li M, Ma Y, Chen Y, Zhang C, Li D and Gu H: Prolonged in vivo circulation time by zwitterionic modification of magnetite nanoparticles for blood pool contrast agents. Contrast Media Mol Imaging 7: 320-327, 2012.

8. Nitta N, Tsuchiya K, Sonoda A, Ota S, Ushio N, Takahashi M, Murata K and Nohara S: Negatively charged superparamagnetic iron oxide nanoparticles: A new blood-pooling magnetic resonance contrast agent. Jpn J Radiol 30: 832-839, 2012.

9. Tsuchiya K, Nitta N, Sonoda A, Nitta-Seko A, Ohta S, Takahashi M, Murata K, Mukaisho K, Shiomi M, Tabata Y and Nohara S: Evaluation of atherosclerotic lesions using dextran- and mannan-dextran-coated USPIO: MRI analysis and pathological findings. Int J Nanomedicine 7: 2271-2280, 2012.

10. Tsuchiya K, Nitta N, Sonoda A, Otani H, Takahashi M, Murata K, Shiomi M, Tabata Y and Nohara S: Atherosclerotic imaging using 4 types of superparamagnetic iron oxides: New possibilities for mannan-coated particles. Eur J Radiol 82: 1919-1925, 2013.

11. Arbab AS, Liu W and Frank JA: Cellular magnetic resonance imaging: Current status and future prospects. Expert Rev Med Devices 3: 427-439, 2006

12. Kawaguchi T, Hanaichi $T$, Hasegawa $M$ and Maruno $S$ : Dextran-magnetite complex: Conformation of dextran chains and stability of solution. J Mater Sci Mater Med 12: 121-127, 2001.

13. Raynal I, Prigent P, Peyramaure S, Najid A, Rebuzzi C and Corot C: Macrophage endocytosis of superparamagnetic iron oxide nanoparticles: Mechanisms and comparison of ferumoxides and ferumoxtran-10. Invest Radiol 39: 56-63, 2004.

14. Neuwelt EA, Hamilton BE, Varallyay CG, Rooney WR, Edelman RD, Jacobs PM and Watnick SG: Ultrasmall superparamagnetic iron oxides (USPIOs): A future alternative magnetic resonance (MR) contrast agent for patients at risk for nephrogenic systemic fibrosis (NSF)? Kidney Int 75: 465-474, 2009.

15. Corot C, Port M, Guibert I, Robert P, Raynal I, Robic C, Raynaud JS, Prigent P, Dencausse A, et al: Superparamagnetic contrast agents, 1st ed. London: CRC Press, 59-84, 2007.

16. Jo J, Aoki I and Tabata Y: Design of iron oxide nanoparticles with different sizes and surface charges for simple and efficient labeling of mesenchymal stem cells. J Control Release 142: 465-473, 2010.

17. Gaur U, Sahoo SK, De TK, Ghosh PC, Maitra A and Ghosh PK: Biodistribution of fluoresceinated dextran using novel nanoparticles evading reticuloendothelial system. Int J Pharm 202: 1-10, 2000.

18. Bulte JW and Kraitchman DL: Iron oxide MR contrast agents for molecular and cellular imaging. NMR Biomed 17: 484-499, 2004.

19. Klasen J, Blondin D, Schmitt P, Bi X, Sansone R, Wittsack HJ, Kröpil P, Quentin M, Kuhlemann J, Miese F, et al: Nonenhanced ECG-gated quiescent-interval single-shot MRA (QISS-MRA) of the lower extremities: Comparison with contrast-enhanced MRA. Clin Radiol 67: 441-446, 2012.

20. Vaage-Nilsen O: Acute, severe and anaphylactoid reactions are very rare with low-molecular-weight iron dextran, CosmoFer. Nephrol Dial Transplant 23: 3372, 2008. 